\title{
Meeting the Challenges of Public Health in India
}

\section{Dr Abraham Joseph,}

Community Health Department,

Christian Medical College, Vellore, India

India is a country of contrasts, with some of the wealthiest people in the world, as well as the greatest number of people living below the poverty line. India probably has the largest labor force, providing the most current information technology, but people in some regions of India must walk for several hours and, at times, for days to access a functioning telephone. Hospitals with the latest medical technologies and highly qualified professionals exist, but vast numbers of the population do not have access to basic health care. India has the health problems of the wealthy (which are similar to that of any high-income country), as well as of the poor- the double health burden. Over 15,000 doctors are certified each year, but areas of the country have only one doctor for over 20,000 people. Yes, it is a country of vast contrasts.

The public health challenge is to meet the needs of this diverse country. According to a World Bank report, only $20 \%$ of the population utilize the government's health care services. The others use private practitioners, both registered and unregistered, as well as polyclinics and corporate hospitals that are expanding in towns and cities. Health care is being commercialized, and corporate hospitals are listed in the share market. However, very few private hospitals are involved in providing public health services, the exception being nongovernmental organizations (NGOs). The contribution of NGOs, though significant in innovation and quality, is negligible in quantity, considering the immense need at the national level. To overcome these deficiencies and to meet the challenges of public health, the following issues need to be addressed.

- $\quad$ Appropriate training of professionals in public health

- Job opportunities
- Establishment of public health laboratories in every district

- Improvement of the health management and information system

- Improved integration of public health and curative services

\section{Appropriate Training of Professionals in Public Health}

While India has contributed to the pool of scientists in the western world (after receiving basic training in India), its contribution of public health professionals is significantly less. Most public health professionals are trained overseas, perhaps attributing to the deficit of Indian training facilities in public health. Although the All India Institute of Public Health was established in 1930, it has not developed to the extent that its founder anticipated. Though national committees periodically have emphasized the need for establishing institutes of public health in this country, very little has been accomplished. This problem must be immediately addressed if India is to meet its public health challenges.

The establishment of an institute of public health can be a financial burden, and, unfortunately, neither private institutions nor the government have been willing to commit themselves to these projects. While the country is proud of the institutes of technology and institutes of management, which was established with considerable financial inputs, it has not made the same commitment for establishing institutes of public health. While entrepreneurs are eager to establish private medical colleges, they have not come forward 
with the same enthusiasm to establish institutes of public health, with a few exceptions. Some countries have indicated their willingness to help establish such institutions through bilateral grants, but governmental response, unfortunately, has been poor. Various national committees and five-year plans have identified this as a priority area, but without adequate commitment to implement this recommendation.

A major reason for this noncommittal attitude could be the financial requirements, both initial and recurring, in establishing such institutions. The financial constraint is felt, not only in this country, but also by well-established institutes of public health in Europe and the United States. The burden of financing such institutions, therefore, falls heavily on the trainees, who must pay an exorbitant fee of approximately $\$ 20,000$ US to complete a year of training in public health. Few candidates are able to undergo this training, unless they are supported by fellowships. In view of the financial constraints, the European institutions have evolved a program known as "Tropmed Europ." Since public health has several sub-specialities, having all of these specialities in one institution is difficult. Therefore, a consortium known as "Tropmed Europ" has been formed. Each institute provides the core curriculum, which lasts three months, and each institute specializes in two or three subjects. The candidates can then choose an area of specialization, which is being offered in one of the consortium universities. The candidates move from the parent institution to another institution for another three months, depending on their subject choices.

India could also follow this model, identifying five or six institutions to teach the common core curriculum. Each institution could then specialize in two or three areas, such as epidemiology, behavioral science, health management, nutrition, maternal and child health, environmental health, occupational health, health education, or health economics. The candidates could then choose two or three of these specialities and transfer to the institutions which conduct the programs of their choice. Currently, there are institutions which are conducting training programs in some of these areas, such as nutrition, occupational health, epidemiology, health management, and health education. These courses could be recognized by a national organization, such as the National Institute of Public Health or other similar institutions. Course accreditation could be completed periodically to ensure that a uniform standard is maintained.

New efforts to reorient public health training should consider the most current learning technologies. A medical unit at Dundee has recommended the SPICE approach-namely, that the program should be Student centered, Problem oriented, Integrated, Community based, and offer Electives (SPICE). Another component to this list could be that the program is Need oriented.

Public health training in this country was started as a diploma in public health. Interestingly, Madras University (one of the earliest universities to offer the diploma), titled the program "Bachelor's in Sanitary Science." As the name implies, the emphasis was on sanitation, the environment, and vector control. Many of the areas, which are a priority today, were not included in the course. Even though many universities in this country offer a diploma in public health, they do not focus on the professional needs of the public health physician. The emphasis in the training needs to concentrate more in areas, such as epidemiology, health management, health economics, behavioral science, environmental science, and primary health care.

The Medical Doctor (MD) of Community Medicine program, of three years duration and initiated in the 1960s, still lacks emphasis in some of these areas. The main purpose of the MD Community Medicine course seems to be training physicians as teachers of public health, with a great deal of the teaching occurring in the classrooms and laboratories.

The first step in implementing a model similar to "Tropmed Europ" would be identifying institutions to form the consortium, with initially only four or five institutions participating. What should be the nature of such institutions? Should they be academic institutions, without any health service responsibility, or should they also have responsibility for health service provision? The weakness of many public health institutions is that they function in isolation, without any clinical or health service responsibilities and must link with institutions 
in other countries for this purpose. While this has its advantages, the disadvantages greatly outweigh them. Unfortunately, in India, the Ministry of Health's decision that each medical college should take responsibility for providing health services, at least, in one block has not been implemented. The ROME program is an example of this. Should one of the criteria for recognizing institutions of public health, under this consortium, be that the institute shall be responsible for providing health services for a defined community, either independently or in collaboration with the local government? When James Grant initiated the Indian Institute of Public Health, it required service responsibility for a community development block. Some of the health policies of the Indian government, soon after independence, were based on the reports from this service area.

The advantage of having service responsibility is that these institutions could carry out essential health research or health systems research, which is vital for our country. National programs are being implemented, without being investigated as pilot studies. I recommend that the "decision cycle" be used, namely, the steps of community diagnosis, prioritization, planning, implementation, monitoring, and evaluation.

One can identify medical colleges in this country which have succeeded in the field of community medicine, and all these institutions, without exception, have a field practice area.

Another important issue, which should be addressed, is whether these institutions should be independent or a component of the medical college. The advantage of being affiliated with a medical college is that students can utilize the medical college resources in the training program, especially for laboratory support and for the clinicians with experience in public health. There are several individuals in this country who have done outstanding work in the public health field, while continuing their clinical responsibilities. Such individuals should have dual teaching responsibilities, both in their parent clinical department as well as in the institute of public health. Another advantage of this linkage is that undergraduate students will be exposed to a higher standard of public health. The disadvantage, however, is that the institute may have a "step-motherly" attitude toward the program.

\section{Job Opportunities for Specialists in Public Health}

Why doesn't public health attract the best candidates from the health professions? In general, it is the last choice of those who fail to get admission to other specialized programs. The answer is rather obvious, when considering the number of applications received for the community medicine course. The choice of a speciality depends on the following:

- Job opportunities in the particular field

- Financial remuneration

- Job satisfaction

Apparently, the public health profession does not satisfactorily fulfill the above parameters. A person who specializes in a clinical subject has many more opportunities, either to work in a large institution or to build a private practice with financial remuneration. The opportunities for public health specialists to have a private practice or to function independently are extremely rare- the exception being a few who serve as consultants for international organizations. Also, these opportunities come only towards the ends of their careers. Those who work in government service are often frustrated by this system, which inhibits their innovativeness. Even more frustrating is that public health specialists rarely become directors of health services, because of the existing policy that only physicians from the central government health services can be selected to that post. Examples of superior public health personnel, who have done extremely well in their own states, exist, but these individuals have not been able to contribute to the national system because of this policy. Since financial remuneration, in limited ways, is one method which could give job satisfaction, this reward should be considered as a high priority, and those professionals exhibiting innovativeness and interest should be rewarded accordingly. 


\section{Improving the Information System for Needs Assessment, Monitoring, and Planning}

The information deficit, or the delay in receiving information, is responsible for many health problems. Although every state, even at the national level, has established health information systems, the process is so slow and inadequate that it is difficult to act on this information to prevent an epidemic, evaluate a program, or establish policies. A few states have initiated steps to modify the information system, but they are in early stages of development, and several committees have been formed at national and state levels to review this problem. Bulletins are published with information obtained from private and government sources, but they are so slow in being collated and published that they do not result in immediate action, although they serve the purpose of periodically reviewing programs. The reorganization of the information system must be completed as soon as possible, so that retrieving and collecting information can be routinely simple and rapid, and the information can be quickly analyzed and disseminated to those who are responsible for managing the program.

\section{Establishment of Public Health Laboratories in Each District}

The delay and difficulty in making an accurate diagnosis during an epidemic is a major problem in India. This problem can cost lives and result in an economic burden; a good example was the plague epidemic of 1995. Financial loss occurred due to the loss of the foreign market and a decrease in tourism. To overcome these lacunae, a public health laboratory must be established in each district. These laboratories can also serve the private practitioners as a referral laboratory, where physicians could send specimens for laboratory confirmation. This type of facility helps decrease the misuse of antibiotics. Rapid diagnosis for clinical conditions is essential for good management, but the disadvantage of using diagnostic kits, which are produced overseas, is that they are costly, and also inappropriate for the local strain of the organism. Kits with a high sensitivity and specificity in the manufacturing country are found to have low sensitivity and specificity when used in India. Hence, effort should be made to develop rapid tests locally and distribute them widely through the public health laboratories. These public health laboratories should also be made available to private practitioners at cost, so that physicians could utilize them to treat their patients with appropriate antibiotics.

\section{Integration between Curative Medicine and Public Health}

Like most other countries, India also faces the problem that there is very little interaction between the clinicians and the public health professionals; thus, a gulf exists, which is becoming increasingly difficult to bridge. Kerr White, in his book, Bridging the Schism, eloquently describes the deficiencies of public health institutions. Some of the communities with the lowest health status in the United States are located in the immediate vicinity of the best public health institutions. This probably occurs because, while these institutions are relevant for international and national purposes, they have little relevance to the local community. This problem could be attributed to the fact that these institutions have no clinical or health service responsibilities. Public health institutions need to think globally, but also act locally.

The Department of Community Health (CMC), from its inception, has integrated clinical and public health activities. This is the strength of the department, which has also enabled the department to have a status similar to that of any other clinical department of the medical college. The departments of community medicine should be more involved in public health services, one of the objectives of the ROME program, which suggested that each medical college take responsibility for health delivery in three community development blocks. The ROME program has, unfortunately, been a major failure because of the lack of commitment of the medical colleges and the department of community health, in particular. The lack of co-operation between academic institutes and the health care system needs to be addressed, and the government, community, and academic profession need to work together. 
Institutions with a responsibility for providing primary health care have several advantages:

- The classes are not theoretical, but practical, and based on relevant community problems.

- The community feels that their health needs are addressed, and citizens then co-operate with the institution's efforts for their training and research programs.

- An opportunity to perform health systems research is provided, which is the most pressing need.

- Community-based research is feasible only when the community realizes that their health needs are being met.

The success of $\mathrm{CMC}$ community-based training and community-based research is primarily due to the services that it provides to a defined community. "Public health cannot be taught in a vacuum" is the slogan.

\section{Integrated Teaching}

Public health, more than curative health, is interdisciplinary in nature and requires good team work.
The team normally consists of doctors, nurses, sociologists, economists, environmentalists, epidemiologists, entomologists, and nutritionists. The MD community medicine and the Doctorate of Public Health (DPH) course is available only to the medical professionals. The Masters of Public Health (MPH) course, on the other hand, is interdisciplinary in nature. This type of interdisciplinary teaching is totally lacking in our country and is an urgent need. If a team is to work together, they need to know the strengths of the other team members; this is best organized when they learn together. "A team that learns together will work best together."

I have attempted to list some of the challenges facing public health teaching. The problems are increasing with rapid globalization. The world is narrowing, so we are discussing a global village. The problems of one village have an impact, not only on the people of the community, but also on the global community. We need to act rapidly. I hope that this workshop will set the pace for public health to meet tomorrow's challenges. India has had a diarrhea of thought and plan, but is constipated in its actions. We need to act quickly, or we will fail in our duties. 